\title{
Metabolic relationships between macro- and micronutrients, and the eicosapentaenoic acid and docosahexaenoic acid contents of Pavlova lutheri
}

\author{
Ana P. Carvalho, Isabel Pontes, Hugo Gaspar, F. Xavier Malcata* \\ Escola Superior de Biotecnologia, Universidade Católica Portuguesa, Rua Dr. António Bernardino de Almeida, \\ P-4200-072 Porto, Portugal
}

Keywords: Aquaculture; Microalgae; Minerals; Polyunsaturated fatty acids

\begin{abstract}
The use of specific microalgae as sources of polyunsaturated fatty acids (PUFA), for incorporation in either aquaculture or human diets, has been receiving increasing interest. The fatty acid profile of intracellular fats in a given species can, within certain limits, be modulated via manipulation of the culture growth conditions, namely nutrient availability. In attempts to shed further light on the effects of chemical parameters upon microalgal metabolism, correlations between the components of a medium and the resulting biomass yield, as well as the eicosapentaenoic acid (EPA) and docosahexaenoic acid (DHA) contents are presented, using Pavlova lutheri as model system. Although several studies of individual nutrients have been published previously, the effects of variation of all medium components upon fatty acid production are systematically presented here, apparently for the first time.

The optimum formulation to optimise EPA and DHA contents should consider the buffering agent, since some of them are toxic to the cells; P. lutheri was able to use several nitrogen sources, yielding equivalent amounts of EPA and DHA; synthesis of EPA was induced in culture media under low salinity, whereas a trend could be noticed between decreasing yields of EPA and increasing concentrations of N, at $0.15 \mathrm{~g} \mathrm{~L}^{-1}$ of P. Regarding the micronutrient composition, a culture medium lacking sulphur was unable to sustain cellular growth, whereas cultures deprived of either calcium, iron or manganese revealed a statistically significant decrease in cellular yields relative to those possessing such minerals; conversely, those cultures without boron produced higher cell numbers than those containing this element. Media deprived of boron, molybdenum or copper led to increases of the relative amounts of both EPA and DHA, whereas calcium deficiency decreased the levels of those PUFA.
\end{abstract}

\section{Introduction}

The nutritional attributes of microalgae depend upon several intrinsic factors, such as their biochemical composition, average size, cell wall digestibility and lack of toxicity. Regarding biochemical composition, high growth rates of zooplankton have been related [1] to diets containing microalgae rich in proteins and specific lipids; the main functions of the latter are to serve as structural components of cell membranes and, when present as storage

\footnotetext{
* Corresponding author. Tel.: +35122 5580004; fax: +351 225090351. E-mail address: fxmalcata@esb.ucp.pt (F.X. Malcata).
}

products, as potential sources of energy and metabolic precursors.

The marine phytoflagellate Pavlova lutheri (Droop) Green (Prymnesiophyceae) is extensively employed by the marine aquaculture industry to feed bivalves at all stages of growth, as well as zooplankton (rotifers, copepods and brine shrimps), which are in turn used to feed crustaceans and fish at larval stages [2]. The main reason for its widespread use derives from its rich fatty acid profile, viz. large amounts of the $n-3$ type polyunsaturated fatty acids (PUFA), eicosapentaenoic acid (EPA) and docosahexaenoic acid (DHA). Although poorly synthesised by many marine animals, these fatty acids are in some cases essential for their normal development; 
when not essential, their inclusion in the diet promotes regular growth and high larval survival rates [2].

Previous studies [2-4] have shown that variations in the fatty acid profile within a given species are observed in response to distinct growth conditions, namely differences in nutrient availability. Studies pertaining to the mineral nutrition of microalgae started in the end of the 19th century; nowadays, it is well established $[5,6]$ that those nutritional needs are characterized by large requirements of carbon (for biomass growth), nitrogen (for protein and chlorophyll synthesis), phosphorus (for energy transfer and other cellular processes), sulphur (for cell division), potassium (for enzyme activation) and magnesium (for chlorophyll synthesis, phosphate transfer and nitrogen metabolism); small requirements of iron (for biological oxidation-reduction and chlorophyll production) and manganese (for chlorophyll synthesis and $\mathrm{O}_{2} / \mathrm{CO}_{2}$ utilization in photosynthesis); and trace requirements of cobalt, zinc (for RNA synthesis and structure), boron, copper (for photosynthesis) and molybdenum (for nitrate assimilation and reduction). Owing to its auxotrophy, $P$. lutheri is also claimed to require small amounts of two vitamins, $\mathrm{B}_{12}$ (cobalamin) and $\mathrm{B}_{1}$ (thiamine- $\mathrm{HCl}$ ), although the latter has apparently a stimulating rather than an essential function [7].

The aforementioned nutritional requirements of microalgae can be satisfied via utilization of various types of culture media. A large number of recipes has indeed been reported, each one claimed to be the most suitable for a particular purpose; however, objective scientific evidence that supports adequacy of each medium to a given microalga is often absent. Consequently, one may choose among a broad range of formulations for cultivation of $P$. lutheri, even though the effects of each ingredient on its metabolism may not have been duly described, or fully established for that matter. Previous studies [8] on the effect of culture media upon the production of PUFA by that microalga demonstrated that higher yields of production are obtained when an enriched seawater medium (GPM) is employed relative to a synthetic one (ASW). Although seawater-based media are easy to prepare in industrial facilities and are associated with low production costs, they are not appropriate if one intends to deepen the knowledge on the specific influence of each chemical constituent; such realisation is a consequence of the wide range of components present in seawater-in fact, virtually all known elements are dissolved to some extent in the ocean water [5], as part of a too complex matrix. Hence, in attempts to clarify the relationship between the mineral composition of the medium and the resulting biotechnological composition of a microalga, one should start from a well-defined basis, i.e. a synthetic culture medium. Consequently, the artificial seawater culture medium designed by Darley and Volcani [9], usually known as ASW, was chosen as a starting model system; the reasoning underlying such a selection relies on the aforementioned comparative studies between ASW and GPM, in terms of composition versus performance during cultivation of $P$. lutheri.
The present communication reports an insight study of the specific medium ingredients that are able to increase cellular yields, as well as EPA and DHA levels in P. lutheri.

\section{Materials and Methods}

\section{Growth conditions}

Pavlova lutheri (SMBA 60) was obtained from the collection held by Instituto Português de Investigação MARítima (IPIMAR), Portugal.

Cultures were grown in ASW medium [9], modified as follows: (i) the initial recipe was enriched with $1 \mathrm{mg} \mathrm{L}^{-1}$ of vitamin $\mathrm{B}_{1}, 2 \mu \mathrm{g} \mathrm{L}^{-1}$ of biotin and $1 \mu \mathrm{g} \mathrm{L}^{-1}$ of vitamin $\mathrm{B}_{12}$ (the same vitamins and concentrations as in GPM medium); (ii) silicates and glycylglycine were removed (the former because of redundancy, and the latter because of being under study); and (iii) EDTA was increased to $50 \mathrm{mg} \mathrm{L}^{-1}$ (similar to its concentration in GPM medium). The $\mathrm{pH}$ was adjusted to 8.0 prior to sterilization. In all experiments, the aforementioned recipe was used as described, except for the component under study, which was subject to deliberate variations either in its chemical form or in its concentration.

Culture flasks were incubated in a controlled environment orbital incubator (Gallenkamp, Sanyo, UK), at $20 \pm 1^{\circ} \mathrm{C}$, under an irradiance level of $75 \mu \mathrm{mol} \mathrm{m}^{-2} \mathrm{~s}^{-1}$-measured with an LI-190SA Quantum Sensor (LI-COR, USA), coupled to an LI-1000 Data Logger, and stirred at $100 \mathrm{rpm}$.

Evolution of the biomass culture was monitored daily, by measurements of optical density. Cultures were harvested in the mid-exponential phase (so as to ensure healthy cells) and sub-cultivated in fresh medium; such procedure was repeated for several generations, after which cultures were maintained until the early stationary phase was reached; they were then collected and analysed for cell mass and fatty acid composition. All experiments were performed in triplicate.

\section{Biomass analyses}

Optical density (OD) was measured spectrophotometrically at $540 \mathrm{~nm}$. Determinations of cell number were performed with a Neubauer Improved bright-line haemocytometer (Superior, Germany). Ash free dry weight (AFDW) was determined by filtering the culture through preconditioned Whatman GF/C glass fibre filters (UK).

\section{Biochemical analyses}

Fatty acids were converted into their methyl ester derivatives by direct transesterification of freeze-dried samples, according to the acidic method described by Lepage and Roy [10] with the modifications introduced by Cohen et al. [11], using heptadecanoic acid as internal standard and acetyl chloride as catalyst. The analysis of those esters was carried out using a gas-liquid chromatographic system (Hewlett Packard 
5890 GC), equipped with a flame ionisation detector and a polar WCOT-fused silica capillary column (50 m length, CPSil 88, Chrompack, The Netherlands). The oven temperature was programmed to increase from 170 to $220^{\circ} \mathrm{C}$ at a rate of $1^{\circ} \mathrm{C} \mathrm{min}^{-1}$; the injector and detector temperatures were 250 and $210^{\circ} \mathrm{C}$, respectively and helium was used as carrier gas at $1.5 \mathrm{~mL} \mathrm{~min}^{-1}$. Pure standards (Sigma) were used for fatty acid identification, which was based on comparison of peak retention times between samples and standards. Peak areas were quantified with an HP-3395 integrator, and calculations were performed according to the AOCS Official Method Ce lb-89 [12].

\section{Statistical analyses}

Depending on the number of independent variables under study in each experiment, one- or two-way analyses of variance were carried out using the software StatView ${ }^{\mathrm{TM}}$ (Abacus Concepts, USA). The difference of means between pairs was resolved by means of confidence intervals, using Fisher's protected least significant difference (P.L.S.D.) test. The level of significance was set at $\alpha=0.05$.

\section{Experimental design}

\section{Buffer}

A factorial design using two buffer compositions (glycylglycine + glycine and Tris- $\mathrm{HCl}$ ), each at two concentrations ( 3 and $6 \mathrm{mM}$ ), was followed. The system composed of glycylglycine and glycine had equivalent proportions of each buffer.

\section{Nitrogen}

The effect of the nitrogen source upon growth and PUFA production by the microalga was investigated with potassium nitrate, ammonium chloride and urea as sole nitrogen sources, coupled with Tris- $\mathrm{HCl}$ as buffer. Nitrogen sources were incorporated in the medium at concentrations equivalent to those present in the original ASW recipe (i.e. $3 \mathrm{mM}$ ).

A control experiment was also performed, without any source of nitrogen.

\section{Nitrogen versus phosphorus}

To screen for interactions between nitrogen and phosphorus uptakes, a factorial design experiment was performed involving those two variables at three levels of concentration each; the intermediate level (control experiment) was the concentration of the compound in the original ASW recipe (i.e. $0.05 \mathrm{~g} \mathrm{~L}^{-1}$ of $\mathrm{K}_{2} \mathrm{HPO}_{4}$ and $0.30 \mathrm{~g} \mathrm{~L}^{-1}$ of $\mathrm{KNO}_{3}$ ), whereas the border concentrations were 0.025 and $0.150 \mathrm{~g} \mathrm{~L}^{-1}$ for $\mathrm{K}_{2} \mathrm{HPO}_{4}$, and 0.15 and $0.90 \mathrm{~g} \mathrm{~L}^{-1}$ for $\mathrm{KNO}_{3}$.

\section{Salinity}

Sodium chloride concentrations, ranging from putative low levels up to those found in highly saline environments were tested in the culture medium; the concentrations used were $5,15,25,35$ and $45 \mathrm{~g} \mathrm{~L}^{-1}$. Given that the amount of sodium chloride in the original ASW recipe was ca. $24 \mathrm{~g} \mathrm{~L}^{-1}$, the control experiment used $25 \mathrm{~g} \mathrm{~L}^{-1}$ of salt.

\section{Oleic acid}

Oleic acid-water soluble powder (containing methyl- $\beta$ cyclodextrin) (SIGMA) was dissolved in water and incorporated into the culture medium at 10 and $30 \mathrm{mg} \mathrm{L}^{-1}$; a control experiment, in the absence thereof, was also performed.

\section{Vitamins}

Studies were carried out on the combined influence of vitamins $B_{1}$ and $B_{12}$ upon growth. Experiments were planned according to a factorial design scheme. The concentrations tested were 0,1 and $10 \mathrm{mg} \mathrm{L}^{-1}$ for vitamin $\mathrm{B}_{1}$, and 0,1 and $10 \mu \mathrm{g} \mathrm{L}^{-1}$ for vitamin $\mathrm{B}_{12}$ (SIGMA). The control experiment contained $1 \mathrm{mg} \mathrm{L}^{-1}$ for vitamin $\mathrm{B}_{1}$ and $1 \mu \mathrm{g} \mathrm{L}^{-1}$ for vitamin $\mathrm{B}_{12}$.

\section{Minerals}

The effects of the elements boron (B), zinc (Zn), copper $(\mathrm{Cu})$, molybdenum $(\mathrm{Mo})$, cobalt $(\mathrm{Co})$, iron $(\mathrm{Fe})$, manganese $(\mathrm{Mn})$, sulphur (S) and calcium (Ca), as well as of the anion tartrate (Tart) in the culture medium, were investigated in an independent fashion. Consequently, the ASW medium was prepared with all compounds, except those which are specific sources of the aforementioned elements; afterwards, that proto-medium was divided into several flasks, and all but one of the aforementioned elements was added to each flask at a time, in the same amount as that set in the ASW recipe. One of the vessels received all nutrients, hence serving as control (T). Boron was used as the chemical form $\mathrm{H}_{3} \mathrm{BO}_{3}$, zinc as $\mathrm{ZnCl}_{2}$, copper as $\mathrm{CuCl}_{2}$, molybdenum as $\mathrm{Na}_{2} \mathrm{MoO}_{4}$, cobalt as $\mathrm{CoCl}_{2}$, iron as $\mathrm{FeSO}_{4}$, manganese as $\mathrm{MnCl}_{2}$, sulphur as both $\mathrm{FeSO}_{4}$ and $\mathrm{MgSO}_{4}$, and calcium as $\mathrm{CaCl}_{2}$, whereas tartrate was used as tartaric acid sodium salt $\left(\mathrm{C}_{4} \mathrm{H}_{4} \mathrm{KNaO}_{6}\right)$ (Merck).

\section{Results}

Apart from the experiment concerning selection of buffer, all remaining experiments used a control culture, i.e. a culture where the parameter(s) under study was/were supplied in the same amount(s) as that/those described in the original ASW recipe.

\section{Selection of buffer}

A preliminary visual observation of the cultures following harvest indicated that the use of distinct buffers produced important differences: the cultures with Tris- $\mathrm{HCl}(\mathrm{T})$ exhibited normal growth, whereas those with glycylglycine and glycine buffers $(\mathrm{G}+\mathrm{G})$ presented poor growth and unhealthy appearance. The average values of $\mathrm{pH}$ variation and optical density for each combination of buffer nature/concentration 
Table 1

Average value \pm standard deviation $(n=3)$ of the effects of source and concentration of buffer on the final $\mathrm{pH}$ and optical density of $P$. lutheri culture

\begin{tabular}{llr}
\hline Buffer & Concentration $(\mathrm{mM})$ & OpH variation \\
\hline Glycylglycine and glycine & 3 & $0.343 \pm 0.004$ \\
Glycylglycine and glycine & 6 & $0.658 \pm 0.095$ \\
Tris- $\mathrm{HCl}$ & 3 & $1.172 \pm 0.083$ \\
Tris- $\mathrm{HCl}$ & 6 & $0.436 \pm 0.018 \mathrm{~b}$ \\
\hline
\end{tabular}

Values followed by the same letter $(\mathrm{a}-\mathrm{c})$ are not statistically different from each other.

Table 2

Average value \pm standard deviation $(n=3)$ of the effects of nitrate, ammonia and urea on biomass, and on EPA and DHA production by $P$. lutheri

\begin{tabular}{|c|c|c|c|c|c|c|}
\hline & \multirow[t]{2}{*}{$\mathrm{pH}$ variation } & \multirow[t]{2}{*}{ Cell count $\left(\times 10^{7} \mathrm{~mL}^{-1}\right)$} & \multicolumn{2}{|c|}{ Fatty acid $\left(\mathrm{mg} \mathrm{L}^{-1}\right)$} & \multicolumn{2}{|l|}{ Fatty acid (\%) } \\
\hline & & & EPA & DHA & EPA & DHA \\
\hline Control & $-0.20 \pm 0.01$ & - & - & - & - & - \\
\hline $\mathrm{NO}_{3}{ }^{-}$ & $+0.51 \pm 0.06$ & $1.61 \pm 0.47 \mathrm{a}$ & $1.24 \pm 0.13 \mathrm{a}$ & $0.70 \pm 0.10 \mathrm{a}$ & $20.25 \pm 0.95 \mathrm{a}$ & $11.65 \pm 2.45 \mathrm{a}$ \\
\hline $\mathrm{NH}_{4}{ }^{+}$ & $-0.22 \pm 0.08$ & $1.27 \pm 0.21 \mathrm{~b}$ & $0.97 \pm 0.24 \mathrm{a}$ & $0.62 \pm 0.10 \mathrm{a}, \mathrm{b}$ & $16.96 \pm 2.56 \mathrm{a}$ & $10.86 \pm 0.77 \mathrm{a}$ \\
\hline Urea & $+0.31 \pm 0.01$ & $0.81 \pm 0.03 \mathrm{c}$ & $0.63 \pm 0.25 \mathrm{a}$ & $0.38 \pm 0.08 \mathrm{~b}$ & $12.25 \pm 3.58 \mathrm{a}$ & $7.35 \pm 0.75 \mathrm{a}$ \\
\hline
\end{tabular}

-: Cultures died after re-inoculation; values followed by the same letter $(\mathrm{a}-\mathrm{c})$ are not statistically different from each other.

are depicted in Table 1 . In terms of $\mathrm{pH}$ variation when using (T) as buffer, one observed that use of $6 \mathrm{mM}$ instead of $3 \mathrm{mM}$ provides a higher buffering capacity, with concomitant decrease of the difference between initial and final $\mathrm{pH}$ values, as expected. Surprisingly, for $(G+G)$ buffers, the lower variation between initial and final $\mathrm{pH}$ values was obtained at $3 \mathrm{mM}$, a fact probably derived from the microscopic observation that the cultures in $6 \mathrm{mM}(\mathrm{G}+\mathrm{G})$ were highly degraded and contained only a few viable cells; hence, due to cell lysis, although there was a higher amount of buffer present, it was not enough to prevent variation in $\mathrm{pH}$.

Concerning the OD values, significantly higher results were observed with $(T)$ when compared with $(G+G)$ at the two levels of buffer concentration tested; within each buffer, the differences in value of OD obtained with 3 and $6 \mathrm{mM}$ were statistically significant for $(G+G)$, but not for $(T)$.

\section{Sources of nitrogen}

The results obtained, both in terms of biomass and PUFA amounts, are presented in Table 2. From inspection of this table, it can be stated that the highest cell yield is obtained when nitrate is used as source of nitrogen, and that such a result is statistically different from the remaining. Regarding the internal amounts of both EPA and DHA, the differences found between the various nitrogen sources are, nevertheless, not statistically significant; in terms of productivities, the only statistically significant difference was observed between use of nitrate or urea towards production of DHA.

\section{Interaction between nitrogen and phosphorus uptake}

The biomass levels, both in terms of cell number and AFDW, of cultures submitted to various combinations of nitrogen (as potassium nitrate) and phosphorus (as potassium hydrogen phosphate) are presented in Table 3 , together with the concentrations of EPA and DHA. (The numbers that denote each experiment do not coincide with the order in which they were performed.) Cell number yields were higher in experiment \#9, which corresponds to the highest amounts of both compounds; nevertheless, this results is statistically

Table 3

Average value \pm standard deviation $(n=3)$ of the effects of nitrogen and phosphorus on biomass, and on EPA and DHA production by $P$. lutheri

\begin{tabular}{|c|c|c|c|c|c|c|c|}
\hline \multirow[t]{2}{*}{ Exp } & \multirow[t]{2}{*}{$\mathrm{P}\left(\mathrm{gL}^{-1}\right)$} & \multirow[t]{2}{*}{$\mathrm{N}\left(\mathrm{g} \mathrm{L}^{-1}\right)$} & \multirow[t]{2}{*}{ Cell count $\left(\times 10^{7} \mathrm{~mL}^{-1}\right)$} & \multicolumn{2}{|l|}{ Fatty acid $\left(\mathrm{mg} \mathrm{L}^{-1}\right)$} & \multicolumn{2}{|l|}{ Fatty acid (\%) } \\
\hline & & & & EPA & DHA & EPA & DHA \\
\hline$\# 1$ & 0.025 & 0.15 & $1.31 \pm 0.19 \mathrm{a}, \mathrm{b}$ & $1.46 \pm 0.06 \mathrm{a}, \mathrm{d}$ & $0.81 \pm 0.05 \mathrm{a}, \mathrm{b}, \mathrm{c}, \mathrm{e}$ & $22.40 \pm 0.85 \mathrm{a}, \mathrm{d}$ & $12.45 \pm 0.16 \mathrm{a}, \mathrm{b}$ \\
\hline \#2 & 0.025 & 0.30 & $1.41 \pm 0.14 \mathrm{a}, \mathrm{b}, \mathrm{c}$ & $1.97 \pm 0.18 b$ & $1.02 \pm 0.01 \mathrm{a}, \mathrm{c}, \mathrm{d}$ & $26.67 \pm 0.06 b$ & $13.90 \pm 1.38 \mathrm{a}, \mathrm{d}$ \\
\hline \#3 & 0.025 & 0.90 & $1.32 \pm 0.08 \mathrm{a}, \mathrm{b}, \mathrm{c}$ & $1.04 \pm 0.23 \mathrm{c}$ & $0.57 \pm 0.03 \mathrm{~b}, \mathrm{e}$ & $19.09 \pm 1.60 \mathrm{c}, \mathrm{d}$ & $10.64 \pm 0.92 b$ \\
\hline$\# 4$ & 0.050 & 0.15 & $1.30 \pm 0.17 \mathrm{a}, \mathrm{b}$ & $1.44 \pm 0.10 \mathrm{a}, \mathrm{d}$ & $0.80 \pm 0.01 \mathrm{a}, \mathrm{b}, \mathrm{c}, \mathrm{e}$ & $22.98 \pm 0.38 \mathrm{a}, \mathrm{d}$ & $12.79 \pm 1.00 \mathrm{a}, \mathrm{b}$ \\
\hline$\# 5$ & 0.050 & 0.30 & $1.39 \pm 0.05 \mathrm{a}, \mathrm{b}, \mathrm{c}$ & $1.39 \pm 0.12 \mathrm{a}, \mathrm{c}, \mathrm{d}$ & $0.71 \pm 0.19 \mathrm{~b}, \mathrm{c}, \mathrm{e}$ & $25.12 \pm 2.37 \mathrm{~b}$ & $12.69 \pm 1.27 \mathrm{a}, \mathrm{b}$ \\
\hline \#6 & 0.050 & 0.90 & $1.23 \pm 0.11 \mathrm{a}$ & $1.53 \pm 0.05 \mathrm{a}$ & $0.96 \pm 0.01 \mathrm{c}, \mathrm{d}, \mathrm{e}$ & $23.35 \pm 1.53 \mathrm{a}, \mathrm{d}$ & $14.70 \pm 11.56 \mathrm{a}$ \\
\hline \#7 & 0.150 & 0.15 & $1.31 \pm 0.15 \mathrm{a}, \mathrm{b}$ & $1.51 \pm 0.06 \mathrm{a}$ & $1.12 \pm 0.25 \mathrm{~d}$ & $21.16 \pm 2.24 \mathrm{~d}$ & $17.53 \pm 1.40 \mathrm{c}$ \\
\hline \#8 & 0.150 & 0.30 & $1.46 \pm 0.05 \mathrm{~b}, \mathrm{c}$ & $1.33 \pm 0.27 \mathrm{a}, \mathrm{c}, \mathrm{d}$ & $0.70 \pm 0.12 \mathrm{e}$ & $21.93 \pm 0.04 \mathrm{~d}$ & $11.56 \pm 0.35 \mathrm{~b}, \mathrm{~d}$ \\
\hline \#9 & 0.150 & 0.90 & $1.51 \pm 0.13 \mathrm{c}$ & $1.11 \pm 0.26 \mathrm{c}, \mathrm{d}$ & $0.71 \pm 0.04 \mathrm{e}$ & $17.21 \pm 0.44 \mathrm{c}$ & $11.15 \pm 1.64 \mathrm{~b}$ \\
\hline
\end{tabular}

Values followed by the same letter (a-e) are not statistically different from each other. 

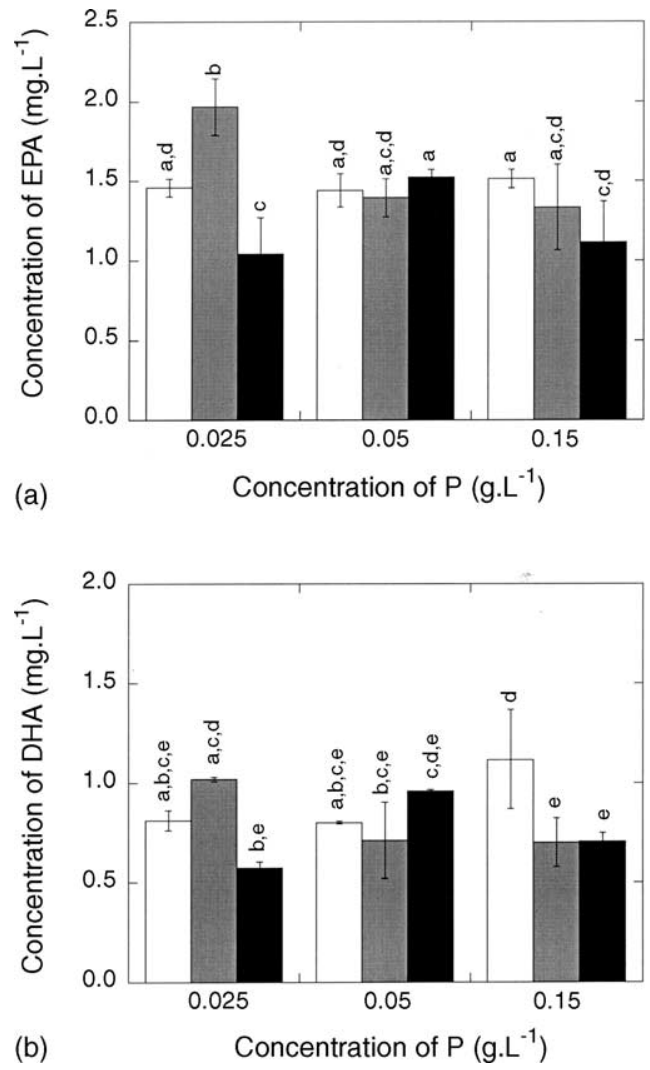

Fig. 1. Simultaneous effects of N and P on EPA (a) and DHA (b) yields: concentrations of $\mathrm{N}$ are denoted by the symbol $(\square)$ for $0.15 \mathrm{~g} \mathrm{~L}^{-1}$, (푤) for $0.30 \mathrm{~g} \mathrm{~L}^{-1}$ and $(\mathbf{\square})$ for $0.90 \mathrm{~g} \mathrm{~L}^{-1}$; bars indicate standard deviation and lettering denotes results of post hoc tests $(n=3)$.

equivalent to those obtained in the experiments \#2, \#3, \#5 and \#8, which share non-limiting levels of nitrogen. Concerning the contents of the PUFA under study, EPA attained its highest value in experiment \#2-which bears the lowest concentration of phosphorus and intermediate levels of nitrogen, whereas the intracellular DHA level was enhanced at the lowest levels of nitrogen and the highest levels of phosphorus (experiment \#7). Statistical analysis of the results revealed equivalent results in terms of EPA content in experiment \#5; in terms of DHA, equivalent results were also obtained in experiments \#2 and \#6. Despite the absence of clear trends pertaining to the effect of $\mathrm{N}$ and $\mathrm{P}$ upon DHA yield (Fig. 1), a trend can be noticed that inversely relates the amounts of $\mathrm{N}$ and the yield of EPA; nevertheless, such trend is only valid for a concentration of $0.15 \mathrm{~g} \mathrm{~L}^{-1}$ of $\mathrm{P}$.

\section{Effect of salinity}

Although the viable cell population increased with decreasing salinity (see Table 4), the total biomass of the culture was similar in all experiments; thus, one concluded that it was not influenced by salinity. Regarding PUFA contents, EPA percent values were not statistically different between the various experiments (apart from the border concentrations of salt), whereas DHA percent values were equivalent for all the experiments; the lower values of salt (up to $15 \mathrm{~g} \mathrm{~L}^{-1}$ for EPA and $25 \mathrm{~g} \mathrm{~L}^{-1}$ for DHA) enhanced productivity yields.

\section{Incorporation of oleic acid}

Oleic acid was incorporated in the culture medium as a possible precursor for synthesis of PUFA. The effects of oleic acid upon growth and cell fatty acid composition are summarized in Table 5. Biomass correlated negatively with the concentration of oleic acid; in terms of percent values of PUFA, the concentration of precursor did not seem to promote any difference in the results, whereas EPA and DHA yields were enhanced in a statistically significant mode in the experiments for which the precursor was absent. Incorporation of oleic acid in microalgal lipids was tentatively analysed by the evolution of oleic acid content (Table 5), as well as the remaining fatty acid contents (results not shown) present in the samples. As the contents of all microalgal fatty acids screened were equivalent between the different concentrations of oleic acid added, there was no apparent incorporation of oleic acid into microalgal lipids.

\section{Effects of vitamins}

Results on the mutual influence of vitamins $B_{1}$ and $B_{12}$, in terms of cell number, are plotted in Fig. 2. If vitamin $B_{12}$ is not supplied, cells will not be viable and the culture will eventually die; however, if a small amount of this vitamin is supplied, the culture will be viable, irrespective of the concentration of vitamin $\mathrm{B}_{1}$ added. There is no statistically significant difference when cells are supplied with 1 or $10 \mu \mathrm{g} \mathrm{L}^{-1}$ of vitamin $\mathrm{B}_{12}$.

Table 4

Average value \pm standard deviation $(n=3)$ of the effect of sodium chloride on biomass, and on EPA and DHA production by $P$. lutheri

\begin{tabular}{rllllll}
\hline $\mathrm{NaCl}\left(\mathrm{g} \mathrm{L}^{-1}\right)$ & Cell count $\left(\times 10^{7} \mathrm{~mL}^{-1}\right)$ & \multicolumn{2}{l}{ Fatty acid $\left(\mathrm{mg} \mathrm{L}^{-1}\right)$} & & & Fatty acid $(\%)$ \\
\cline { 3 - 4 } & & EPA & & EPA & \\
\hline 5 & $1.52 \pm 0.03 \mathrm{a}$ & $4.61 \pm 0.42 \mathrm{a}$ & $2.94 \pm 0.45 \mathrm{a}$ & & $20.56 \pm 0.17 \mathrm{a}$ & $13.08 \pm 0.71 \mathrm{a}$ \\
15 & $1.20 \pm 0.06 \mathrm{~b}$ & $4.77 \pm 0.01 \mathrm{a}$ & $2.60 \pm 0.04 \mathrm{a}$ & & $23.02 \pm 0.53 \mathrm{~b}, \mathrm{c}$ & $12.53 \pm 0.05 \mathrm{a}$ \\
25 & $1.14 \pm 0.11 \mathrm{~b}$ & $3.90 \pm 0.14 \mathrm{~b}$ & $2.25 \pm 0.21 \mathrm{a}$ & & $23.40 \pm 0.10 \mathrm{~b}, \mathrm{c}$ & $14.11 \pm 0.08 \mathrm{a}$ \\
35 & $1.10 \pm 0.14 \mathrm{~b}$ & $3.14 \pm 0.01 \mathrm{c}$ & $1.51 \pm 0.01 \mathrm{~b}$ & & $24.59 \pm 0.13 \mathrm{~b}$ & $11.84 \pm 0.07 \mathrm{a}$ \\
45 & $1.21 \pm 0.13 \mathrm{~b}$ & $2.96 \pm 0.06 \mathrm{c}$ & $1.39 \pm 0.34 \mathrm{~b}$ & & $22.01 \pm 1.94 \mathrm{a}, \mathrm{c}$ & $10.45 \pm 3.27 \mathrm{a}$ \\
\hline
\end{tabular}

Values followed by the same letter $(\mathrm{a}-\mathrm{c})$ are not statistically different from each other. 
Table 5

Average value \pm standard deviation $(n=3)$ of the effect of oleic acid on human, and on EPA, DHA and oleic acid production by $P$. lutheri

\begin{tabular}{|c|c|c|c|c|c|c|}
\hline \multirow[t]{2}{*}{ Oleic acid $\left(\mathrm{mg} \mathrm{L}^{-1}\right)$} & \multirow[t]{2}{*}{ Cell count $\left(\times 10^{7} \mathrm{~mL}^{-1}\right)$} & \multicolumn{2}{|c|}{ Fatty acid $\left(\mathrm{mg} \mathrm{L}^{-1}\right)$} & \multicolumn{3}{|l|}{ Fatty acid (\%) } \\
\hline & & EPA & DHA & EPA & DHA & Oleic acid \\
\hline 0 & $1.68 \pm 0.11 \mathrm{a}$ & $2.11 \pm 0.30 \mathrm{a}$ & $0.87 \pm 0.07 \mathrm{a}$ & $19.21 \pm 1.77 \mathrm{a}$ & $7.94 \pm 0.22 \mathrm{a}$ & $1.59 \pm 0.50 \mathrm{a}$ \\
\hline 10 & $1.45 \pm 0.16 \mathrm{~b}$ & $0.67 \pm 0.16 \mathrm{~b}$ & $0.32 \pm 0.11 b$ & $13.12 \pm 1.94 b$ & $6.21 \pm 1.59 \mathrm{a}$ & $2.34 \pm 0.66 \mathrm{a}$ \\
\hline 30 & $1.09 \pm 0.11 \mathrm{c}$ & $0.78 \pm 0.05 \mathrm{~b}$ & $0.40 \pm 0.04 \mathrm{~b}$ & $15.36 \pm 1.17 \mathrm{a}, \mathrm{b}$ & $7.93 \pm 0.05 \mathrm{a}$ & $2.47 \pm 0.30 \mathrm{a}$ \\
\hline
\end{tabular}

Values followed by the same letter $(\mathrm{a}-\mathrm{c})$ are not statistically different from each other.

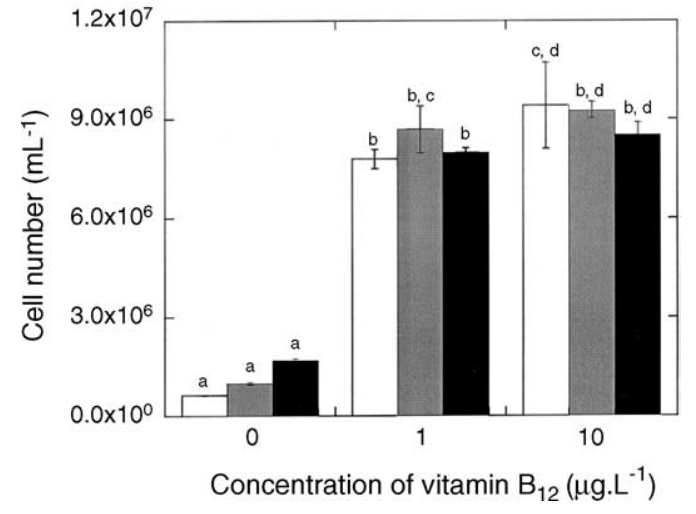

Fig. 2. Effects of vitamins $\mathrm{B}_{1}$ and $\mathrm{B}_{12}$ upon cellular numbers of $P$. lutheri culture: concentrations of vitamin $B_{1}$ are denoted by the symbol $(\square)$ for

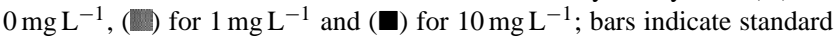
deviation and lettering denotes results of post hoc tests $(n=3)$.

\section{Effects of minerals}

Cultures in media deprived of S died after the second reinoculation, and thus are not represented in the figures. Those cultures without $\mathrm{Cu}$ or Mo were statistically equivalent to the culture containing all nutrients $(\mathrm{T})$ in terms of cell number, whereas the remaining were statistically different (see Fig. 3); cultures without B produced higher cell numbers than those possessing such an element. The relative fractions of EPA and DHA in the various culture media tested are depicted in Figs. 4 and 5: for both fatty acids, $\mathrm{T}$ did not provide the highest

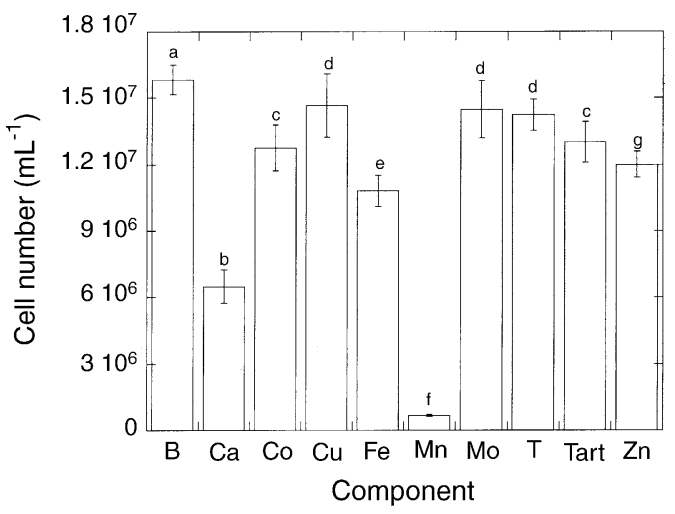

Fig. 3. Effect of components of the culture medium on cellular numbers of $P$. lutheri culture; bars indicate standard deviation and lettering denotes results of post hoc tests and lettering denotes results of post hoc tests $(n=3)$.

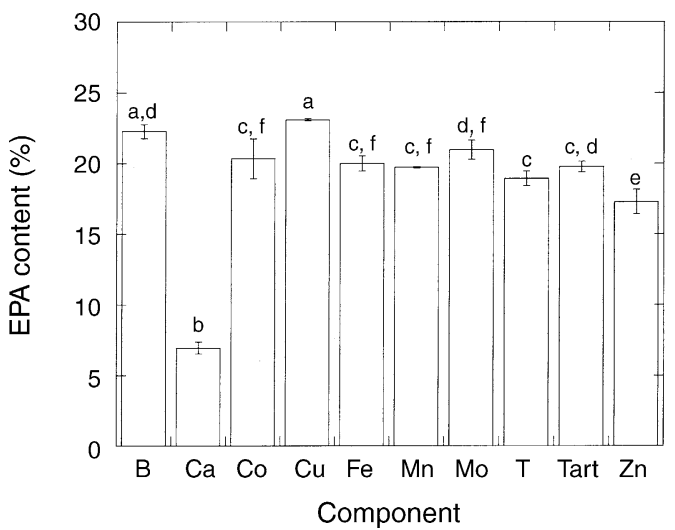

Fig. 4. Effect of components of the culture medium on EPA amount of $P$. lutheri culture; bars indicate standard deviation $(n=3)$.

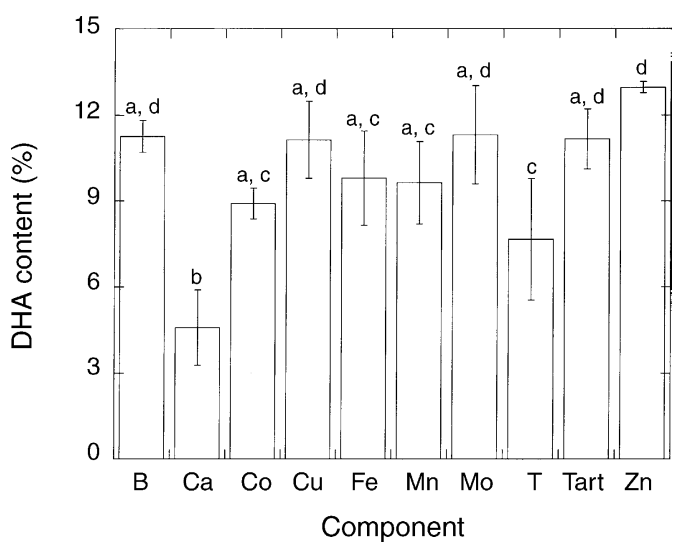

Fig. 5. Effect of components of the culture medium on DHA amount of $P$. lutheri culture; bars indicate standard deviation and lettering denotes results of post hoc tests $(n=3)$.

levels of PUFA; in fact, the highest values were observed in the cultures without $\mathrm{B}, \mathrm{Cu}$ and Mo in the case of EPA, and in the cultures without $\mathrm{B}, \mathrm{Cu}, \mathrm{Mo}$, Tart and $\mathrm{Zn}$ in the case of DHA.

\section{Discussion}

In order to ensure feasible application, marine culture media should satisfy several requirements, viz: (i) formulation should be simple, yet contain all essential elements/compounds in sufficient amounts; (ii) components should be easily measured and mixed; (iii) ions should be 
present in concentrations and proportions close to those found in natural seawater (so as to guarantee essentially identical ionic strength); and (iv) constituent salts should not precipitate easily [5].

\section{Selection of buffer}

As microalgae react differently in the presence of distinct buffers, selection of the most appropriate for a specific microalga is a crucial step in the development of optimum growth conditions. Tris- $\mathrm{HCl}$ (Tris-hydroxymethylaminomethan) is the standard buffer used in the physiological $\mathrm{pH}$ range [13], whereas glycylglycine is referred to as much less toxic to some species than Tris [14], although bearing a buffering capacity appropriate for lower $\mathrm{pH}$ values; an equimolar mixture of glycylglycine and glycine (in theory) would provide a buffer solution that is less toxic to the cells and which possesses an increased buffering capacity in the $\mathrm{pH}$ range 9-10. Our experimental data indicate that use of $(\mathrm{G}+\mathrm{G})$ or $(\mathrm{T})$ as buffer agents is not equivalent; the former promotes undesirable side effects, viz. cell lysis (and concomitant decrease in OD), probably owing to the presence of some compound toxic to the cells. Such toxicity may likely be attributed to glycylglycine, since similar results had already been observed in our laboratory (unpublished data); this finding is quite interesting, because this buffer has been proposed in the literature as a substitute for Tris- $\mathrm{HCl}$ due to its lower toxicity [14].

Utilization of 3 or $6 \mathrm{mM}$ as buffer concentration does not significantly affect the OD values within the (T) buffer; for $(G+G)$, the differences observed were statistically significant but, as previously pointed out, such differences were due to the increased amount of cell lysis, which promoted dramatic variations in $\mathrm{pH}$ that overcome the buffering capacity of $(G+G)$. In conclusion, Tris should be used to buffer culture media of $P$. lutheri.

\section{Sources of nitrogen}

Second to carbon (and provided that hydrogen and oxygen, which can be obtained from water, are ignored), nitrogen is the most important element in the constitution of algal cells; its proportion as percent dry weight lies in 1-10\% [15]. A variety of nitrogen compounds, both inorganic and organic in nature, can be used as nitrogen sources for growth of prokaryotes and eukaryotes. The capacity to fix gaseous nitrogen is confined to the former, but the ability to use nitrate, nitrite, ammonia or urea appears to be general among microalgae. Pavlova lutheri can use a variety of inorganic nitrogen sources, whereas urea appears to be the only usable organic source [13]; our results are consistent with that report. As the different sources of nitrogen do not affect EPA and DHA yields, the choice of the source for use in the culture medium will not be dictated by yield, but rather by such other criteria as cost of the raw material or susceptibility to bacterial degradation.

\section{Interaction between nitrogen and phosphorus uptake}

Apart from nitrogen, phosphorus is also one of the major nutrients required for normal growth of microalgae. It plays a role in most cellular processes, particularly those involved in energy transfer and nucleic acid synthesis [15]. Short-term phosphate uptake from the culture medium was reported [16] to be independent of nitrate concentration, whereas short-term nitrate uptake rate was reduced in the presence of phosphate. Hence, investigation of nutrient uptake interactions may be of importance with regard to nitrogen and phosphorus, due to their mutually competitive removal from the medium. Gallegos and Jordan [17] demonstrated that nitrogen addition enhances phytoplankton growth rate more frequently and to a greater extent than addition of phosphorus alone; our results are in agreement with such a statement, as they unfolded a correlation between high cellular yields and non-limitation of nitrogen. Regarding the effect of nitrogen and phosphorus on EPA and DHA contents, a trend can be noticed between decreasing yields of EPA at increasing concentrations of $\mathrm{N}$, although only for $0.15 \mathrm{~g} \mathrm{~L}^{-1}$ of $\mathrm{P}$. Such a result is confirmed by the information conveyed by ANOVA, which defined the simultaneous effect of $\mathrm{N}$ and $\mathrm{P}$ as statistically significant for both fatty acids, whereas the single effect of $\mathrm{N}$ was significant only for EPA, and the individual effect of $\mathrm{P}$ was not significant for either $\mathrm{N}$ or $\mathrm{P}$.

The experimental conditions prevailing in control culture (\#5) did not lead to the highest figures, in terms of cell number or fatty acid amount; hence, when cultivating $P$. lutheri, one should modify the amounts of $\mathrm{N}$ and $\mathrm{P}$ provided to those used in experiment \#2 (as these amounts bring about cell numbers equivalent to those of experiment \#9-the highest yield of EPA and a yield of DHA equivalent to that of experiment \#7).

\section{Effect of salinity}

The lumen of all cell membranes has a hydrophobic environment, due to their fatty acid constituents-which form an impermeable barrier to water and polar molecules. The physical properties of the membrane are determined by the individual lipids therein, as well as by the fatty acid components of those lipids and their interaction with the other components (e.g. proteins) [18]. The interactions of microalgal cells with their surrounding environment bring about modifications of the membrane lipid composition, namely chemical changes in their fatty acid profile; the effects of salinity upon cell growth and fatty acid profile have already been described for a few microalgal species [19,20]. The degree of unsaturation of the fatty acids is directly related to the fluidity and conformation of cellular membranes, and hence to their capacity of providing the correct environment for the various membrane functions; therefore, any changes in their fatty acid composition may be interpreted in terms of regulation of membrane fluidity/conformation, 
aimed at adapting them to a new evolving growth environment [18]. Increasing salinity of the growth medium (above a given threshold) led to decreases of EPA amount, whereas the level of DHA was affected only when the levels of salt were even higher. Such a correlation had already been reported for arachidonic acid in Porphyridium cruentum [21] and for EPA in Phaeodactylum tricornutum [22]. ChiniZittelli et al. [23] reported modifications in the fatty acid profile of Nannochloropsis sp. with salinity, although the EPA content of the biomass was not significantly affected. It is possible that a less fluid membrane (i.e. with lower amounts of PUFA) might help prevent the efflux of water from the cells under hypertonic conditions, hence preserving cell integrity. Such other compounds as sucrose, manitol or sorbitol have an osmotic effect similar to that of sodium chloride $[18,24]$, so the proper environment necessary for this osmotic phenomenon to take place is a certain level of osmotic pressure raised within the medium, rather than a high salt concentration.

\section{Incorporation of oleic acid}

Oleic acid was incorporated into the culture medium as a possible precursor toward synthesis of PUFA. Media containing free fatty acids have been reported [22] to either suppress the biosynthesis of other fatty acids or enhance production of PUFA. Recall that a decrease in cell numbers and a constancy of percent values of EPA and DHA were observed when the precursor, oleic acid, was present; this may suggest that there was an inhibiting growth factor in the medium, which could be methyl- $\beta$-cyclodextrin (used by the supplier to stabilize the oleic acid water-soluble powder). Such substance reduced growth and limited incorporation of oleic acid in microalgal lipids; in fact, apart from EPA, DHA and oleic acid, the percent values of all the remaining fatty acids present in the samples were equivalent to each other for the three concentrations of oleic acid added-so, there was apparently no incorporation of oleic acid.

\section{Effects of vitamins}

Thiamine $\left(\mathrm{B}_{1}\right)$ and cyanocobalamin $\left(\mathrm{B}_{12}\right)$ are the vitamins of the $\mathrm{B}$ complex most frequently cited as required by algal flagellates and diatoms [14,25]. The latter is claimed [7] to be essential for $P$. lutheri, whereas vitamin $\mathrm{B}_{1}$ is supposed to act as a stimulant. Since the requirement for vitamin $B_{12}$ is rather small (each picogram of vitamin supports the growth of $0.6 \times 10^{6}$ cells) [26], the cultures supplied with $1 \mu \mathrm{g} \mathrm{L}^{-1}$ were not growth-limited, so the increased availability of said vitamin in the cultures at $10 \mu \mathrm{gL}^{-1}$ did not promote any significant increase in cell growth. Cell numbers were statistically equivalent irrespective of the amounts of vitamin $\mathrm{B}_{1}$, hence indicating its non-essential effect (which was further confirmed by the statistical analysis).

\section{Effects of minerals}

No medium can be considered adequate to support microalgal growth unless it provides several micronutrients. These elements, which by definition are required in very small amounts (at the micro-, nano- or picogram per litre level) share several other characteristics: (i) they influence growth of a representative number of species; (ii) show a direct physiological effect upon algal growth; (iii) cannot be replaced by other elements; and (iv) induce reversible symptoms of deficiency in cultures lacking them. Some of the major trace elements in algal media are $\mathrm{Mn}, \mathrm{Zn}, \mathrm{B}, \mathrm{Co}$, $\mathrm{Cu}$ and Mo. From the single-variable optimisation strategy employed, one concluded that some nutrients are not essential for growth: the media without B induced cell yields statistically higher than those conveyed by media with all nutrients included (T). Fabregas et al. [27] also demonstrated that vanadium, iodine, B and $\mathrm{Zn}$ were non-essential for growth of Haematococcus pluvialis. $\mathrm{S}$ is a macro-element essential to all organisms in the form of sulphur-containing amino acids [15]; hence, a medium deprived thereof cannot sustain algal growth, as actually observed. Cultures deprived of either $\mathrm{Ca}, \mathrm{Fe}$ or $\mathrm{Mn}$ revealed cellular yields significantly below those obtained in complete media $(\mathrm{T})$. Ca requirement for maximum growth has been demonstrated for a few microalgae, although its function remains largely unknown; $\mathrm{Fe}$ is used by cells for biological oxidation-reduction and chlorophyll production, and manganese is used for chlorophyll synthesis and $\mathrm{O}_{2} / \mathrm{CO}_{2}$ utilization in photosynthesis $[5,6]$. The absence of $\mathrm{Cu}$ or Mo had no significant effect on growth.

Regarding PUFA production, the absence of B, Mo and $\mathrm{Cu}$ in the medium promoted increases in the relative amounts of EPA, whereas the absence of the former as well as $\mathrm{Zn}$ and Tart had equivalent effects on DHA. $\mathrm{B}$ and $\mathrm{Cu}$ are essential components of the photosynthetic electron transport system, as well as of several other enzymes [15]; although considered essential at extremely low concentrations, $\mathrm{Cu}$ becomes toxic at higher concentrations [6]. Mo is essential for nitrate assimilation and reduction in eukaryotic algae-its absence diminishes the nitrate uptake mechanism, thus interfering with lipid synthesis. Zn is used for RNA synthesis and structure, whereas $\mathrm{K}$ (from Tart) is linked to enzyme activation $[5,6]$. Both EPA and DHA were significantly reduced in culture media without $\mathrm{Ca}$, whereas the absence of $\mathrm{Co}, \mathrm{Fe}$ and $\mathrm{Mn}$ was not statistically significant. However, it must be noted that the Co-free media had, in fact, traces of this element (bound to vitamin $\mathrm{B}_{12}$ ), which could be enough to provide non-limiting growth and PUFA production.

In view of the above, instead of using all the chemical elements present in the original ASW recipe (control culture), culture medium should be prepared without either $\mathrm{B}, \mathrm{Cu}$ and Mo, as their presence is associated with lower amounts of EPA and DHA; furthermore, the absence of B favours cell numbers, whereas $\mathrm{Cu}$ and Mo do not seem to interfere with those figures. 


\section{Conclusions}

The production of EPA and DHA from $P$. lutheri in an artificial seawater culture medium (ASW) requires several adjustments in terms of macro- and micronutrient supply, in order to both fulfil the microalga requirements in terms of growth and supply the adequate chemical environment to enhance PUFA synthesis. In this study, several relationships between components of the medium and both growth and PUFA production were traced. As a result, the ASW recipe tailored to enhance PUFA production should be buffered with Tris- $\mathrm{HCl}$, contain lower amounts of $\mathrm{P}\left(0.025 \mathrm{~g} \mathrm{~L}^{-1}\right)$ than the original recipe, contain reduced levels of salt, and be free of $\mathrm{B}, \mathrm{Cu}$ and $\mathrm{Mo}$.

\section{Acknowledgement}

Financial support for author Carvalho (grant no. BD/2838/93-IF) by PRAXIS XXI (Portugal) is hereby acknowledged.

\section{References}

[1] Renaud SM, Thinh L, Lambrinidis G, Parry DL. Effect of temperature on growth, chemical composition and fatty acid composition of tropical Australian microalgae grown in batch cultures. Aquaculture 2002;211:195-214.

[2] Volkman JK, Jeffrey SW, Nichols PD, Rogers GL, Garland CD. Fatty acid and lipid composition of 10 species of microalgae used in mariculture. J Exp Mar Biol Ecol 1989;128:219-40.

[3] Fernández-Reiriz MJ, Perez-Camacho A, Ferreiro MJ, Blanco J, Planas M, Campos MJ, et al. Biomass production and variation in the biochemical profile (total protein, carbohydrates, RNA, lipids and fatty acids) of seven species of marine microalgae. Aquaculture 1989;83:17-37.

[4] Dunstan GA, Volkman JK, Barret SM, Garland CD. Changes in the lipid composition and maximization of the polyunsaturated fatty acid content of three microalgae grown in mass culture. J Appl Phycol 1993;5:71-83.

[5] Spotte S. Culture media. In: Seawater aquariums-the captive environment. New Jersey: Wiley; 1979. p. 26-54.

[6] Becker EW. Culture media. In: Microalgae-biotechnology and microbiology. Cambridge: Cambridge University Press; 1994. p. 9-41.

[7] Droop MR. Cobalamin requirement in Chrysophyceae. Nature 1954;174:520.

[8] Carvalho AP, Malcata FX. Effect of culture media on production of polyunsaturated fatty acids by Pavlova lutheri. Cryptog Algol 2000;21:59-71.
[9] Borowitzka MA. Algal growth media and sources of algal cultures. In: Micro-algal biotechnology. Cambridge: Cambridge University Press; 1988. p. 456-465.

[10] Lepage G, Roy C. Improved recovery of fatty acid through direct transesterification without prior extraction or purification. J Lipid Res 1984;25:1391-6.

[11] Cohen Z, Vonshak A, Richmond A. Effect of environmental conditions on fatty acid composition of the red alga Porphyridium cruentum: correlation to growth rate. J Phycol 1988;24:32832.

[12] Firestone D. Method Ce 1b-89. In: The official methods and recommended practices of the American Oil Chemists' Society. 1994.

[13] Antia NJ, Berland BR, Bonin DJ, Maestrini SY. Comparative evaluation of certain organic and inorganic sources of nitrogen for phototropic growth of marine microalgae. J Mar Biol Assoc UK 1975;55:519-39.

[14] Droop MR. Requirement for thiamine among some marine and supra-littoral protista. J Mar Biol Assoc UK 1958;37:323-9.

[15] Richmond AE. Algal nutrition. In: CRC handbook of microalgal mass culture. Florida: CRC Press; 1986. p. 69-99.

[16] Terry KL. Nitrate and phosphate uptake interactions in a marine Prymnesiophyte. J Phycol 1982;18:79-86.

[17] Gallegos CL, Jordan TE. Seasonal progression of factors limiting phytoplankton pigment biomass in the Rhode river estuary, Maryland (USA). 2. Modeling N versus P limitation. Mar Ecol Progr Ser 1997;161:199-212.

[18] Xu XQ, Beardall J, Hallam D. Modification of fatty acid composition in halophilic antarctic microalgae. Phytochemistry 1998;49:124952.

[19] Xu XQ, Beardall J. Effect of salinity on fatty acid composition of a green microalga from an antarctic hypersaline lake. Phytochemistry 1997;45:655-8.

[20] Jiang Y, Chen F. Effects of salinity on cell growth and docosahexaenoic acid content of the heterotrophic marine microalga Crypthecodinium cohnii. J Ind Microbiol Biotechnol 1999;23:508-13.

[21] Lee YK, Tan HM, Low CS. Effect of salinity of medium on cellular fatty acid composition of marine alga Porphyridium cruentum (Rhodophyceae). J Appl Phycol 1989;1:19-23.

[22] Yongmanitchai W, Ward OP. Growth and omega-3 fatty acid production by Phaeodactylum tricornutum under different culture conditions. Appl Environ Microbiol 1991;57:419-25.

[23] Chini-Zittelli G, Lavista F, Bastianini A, Rodolfi L, Vincenzini M, Tredici MR. Production of eicosapentaenoic acid by Nannochloropsis sp. cultures in outdoor tubular photobioreactors. J Biotechnol 1999;70:299-312.

[24] Craigie JS. Some salinity-induced changes in growth, pigments and cyclohexanetetrol content of Monochrysis lutheri. J Fish Res Board Can 1969;26:2959-67.

[25] Droop MR. Auxotrophy and organic compounds in the nutrition of marine phytoplankton. J Gen Microbiol 1957;16:286-93.

[26] Droop MR. vitamin $B_{12}$ and marine ecology: the response of Monochrysis lutheri. J Mar Biol Assoc UK 1961;41:69-76.

[27] Fabregas J, Dominguez A, Regueiro M, Maseda A, Otero A. Optimization of culture medium for the continuous cultivation of the microalga Haematococcus pluvialis. Appl Microbiol Biotechnol 2000;53:530-5. 